Check for updates

Cite this: RSC Adv., 2019, 9, 16040

Received 6th May 2019

Accepted 7th May 2019

DOI: $10.1039 / \mathrm{c} 9 \mathrm{ra0} 3389 \mathrm{k}$

rsc.li/rsc-advances

\section{Transition-metal-free amination phosphoryl azide for the synthesis of phosphoramidates $\uparrow$}

\author{
Qing Li,,$^{a}$ Xiaohua Sun, $t^{b}$ Xiaoqin Yang, $t^{a}$ Minghu Wu, Shaofa Sun ${ }^{a}$ \\ and Xiuling Chen (D)*a
}

A facile and efficient approach to phosphoramidates was developed via amination of phosphoryl azides. A variety of phosphoramidates were obtained in one step with good to excellent yields under a mild reaction system. The process uses easily available amines as a $\mathrm{N}$ source and offers a new opportunity for $\mathrm{P}-\mathrm{N}$ bond formation.
Organophosphorus compounds are an important structural feature in pharmaceutical chemistry, biological and materials chemistry. ${ }^{1,2}$ Among organophosphorus compounds, phosphoramidates are prevalent organic structural motifs widely applied in industry as pharmaceutical prodrugs, medicinal areas that have potent antifungal, antitumor, and anti-HIV activities, and in analytical chemistry to restrain matrixrelated ion effects in MALDI-TOF mass spectrometry and improve ionization efficiency. Additionally, phosphoramidates are also important precursors for the synthesis of flame retardants. ${ }^{3-8}$ Moreover, in recent years, phosphoramidates have become important chiral ligands for several metal-catalyzed reactions. ${ }^{9}$ For these reasons, the synthesis of phosphoramidates is of great importance. Generally, synthetic procedures for the preparation of phosphoramidates rely on the reaction of phosphorus halides and amines, $\mathrm{P}(\mathrm{III})$ as the reagent and corrosive materials but low functional group tolerance and complex operations have limited this application. ${ }^{10}$ To overcome these problems, alternative methods for phosphoramidates synthesis have been developed. ${ }^{11-16}$ The AthertonTodd reaction represents an alternative route for the synthesis of phosphoramidates, but this approach also is far from ideal due to the use of stoichiometric $\mathrm{CCl}_{4}$, which presents a limitation to an environmentally friendly method. ${ }^{11}$ Recently, a catalyzed oxidative dehydrocoupling of $\mathrm{P}(\mathrm{O}) \mathrm{H}$ bonds with amines reaction has emerged as a green synthetic tool. However, transition metals, halogen or additional additives are required. ${ }^{12}$ Other methods include a Lewis acid-catalyzed phosphorimidate rearrangement to $N, N$-disubstituted phosphoramidates,

\footnotetext{
${ }^{a}$ Non-power Nuclear Technology Collaborative Innovation Center, School of Nuclear Technology and Chemistry \& Biology, Hubei University of Science and Technology, Xianning 437100, China.E-mail: cxl828800@163.com; sunshaofa@mail.hbust.com. cn; Fax: +86-715-8338007

${ }^{b} X i a n n i n g$ Vocational Technical College, China

$\dagger$ Electronic supplementary information (ESI) available: Experimental procedures, characterization data for the products. See DOI: 10.1039/c9ra03389k

$\ddagger$ These authors contributed equally to this work.
}

nucleophilic addition of $\mathrm{TMSCCl}_{3}$ to $\mathrm{N}$-phosphinoyl benzaldimines ${ }^{13}$ the addition of diarylphosphine oxides to azobenzenes to construct a N-N-P unit, ${ }^{14}$ and a lanthanum-catalyzed direct double hydrophosphinylation of unactivated nitriles to phosphoramidates. ${ }^{15}$ Although these protocols have widespread utility, they usually suffer from some intrinsic disadvantages, as they rely on transition metals or are sensitive to water or oxygen.

Recently, transition metal catalyzed $\mathrm{C}-\mathrm{H}$ phosphoramidation of different substrates with a phosphoryl azide to provide various $N$-aryl phosphoramidates has been developed. ${ }^{16}$ However, transition metal catalysts are toxic, especially for use in the drug and pharmaceutical industries. Therefore, a metalfree condition, convenient and green method to synthesize phosphoramidates is still desired. Herein, we report an environmentally friendly approach for the preparation of phosphoramidates via amination of phosphoryl azide (eqn (1)). Our system covers a wide range of amine substrates under mild conditions for preparing highly functionalized phosphoramidates with ease.

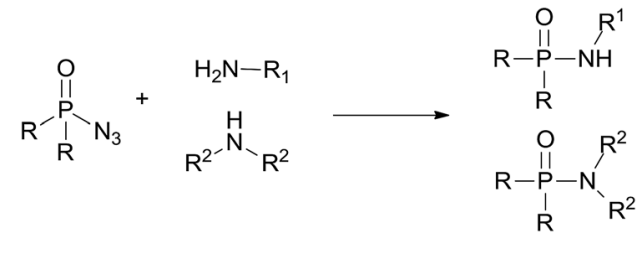

To explore the practicability of this novel amination phosphoryl azide protocol, we choose diphenyl phosphoryl azide (1a) and $n$-propylamine (2a) as model substrates to optimize the reaction conditions, and the obtained results are compiled in Table 1. First, $\mathrm{Cs}_{2} \mathrm{CO}_{3}$ was used as a base to attempt the amination phosphinyl azides reaction when dioxane was used as solvent at $120{ }^{\circ} \mathrm{C}$, and $\mathbf{3 a}$ was obtained in $31 \%$ yield (Table 1 , entry 1). Next, various solvents including THF, toluene, $\mathrm{CH}_{3} \mathrm{CN}$, $\mathrm{CH}_{3} \mathrm{COOC}_{2} \mathrm{H}_{5}, \mathrm{C}_{2} \mathrm{H}_{5} \mathrm{OH}, \mathrm{DMF}$, and DMSO were screened (Table 1, entries 2-8), and DMF was found to the best choice to give 
Table 1 Optimization of the reaction conditions ${ }^{a}$

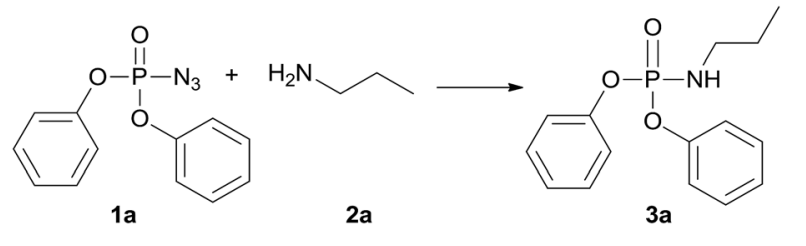

\begin{tabular}{llll}
\hline Entry & Solvent & Additive & Yield of 3a \\
\hline 1 & Dioxane & $\mathrm{Cs}_{2} \mathrm{CO}_{3}$ & 31 \\
2 & THF & $\mathrm{Cs}_{2} \mathrm{CO}_{3}$ & 25 \\
3 & Toluene & $\mathrm{Cs}_{2} \mathrm{CO}_{3}$ & 44 \\
4 & $\mathrm{CH}_{3} \mathrm{CN}$ & $\mathrm{Cs}_{2} \mathrm{CO}_{3}$ & 51 \\
5 & $\mathrm{CH}_{3} \mathrm{COOC} \mathrm{H}_{5}$ & $\mathrm{Cs}_{2} \mathrm{CO}_{3}$ & 36 \\
6 & $\mathrm{C}_{2} \mathrm{H}_{5} \mathrm{OH}$ & $\mathrm{Cs}_{2} \mathrm{CO}_{3}$ & - \\
7 & $\mathrm{DMSO}$ & $\mathrm{Cs}_{2} \mathrm{CO}_{3}$ & - \\
8 & $\mathrm{DMF}$ & $\mathrm{Cs}_{2} \mathrm{CO}_{1}$ & 69 \\
9 & $\mathrm{CMF}$ & $\mathrm{CuCl}_{2}$ & 30 \\
10 & $\mathrm{DBU}$ & - & 46 \\
11 & $\mathrm{DMF}$ & - & 84 \\
$12^{c}$ & $\mathrm{DMF}$ & - & 32 \\
$13^{d}$ & $\mathrm{DMF}$ & & -
\end{tabular}

${ }^{a}$ Reaction conditions: diphenyl phosphoryl azide 1a (0.2 mmol), $n$ propylamine $2 \mathrm{a}(0.4 \mathrm{mmol})$, base $(2.0$ equiv.), dioxane $(2 \mathrm{~mL})$, in a $25 \mathrm{~mL}$ Schlenk tube, $120{ }^{\circ} \mathrm{C}, 12 \mathrm{~h} .{ }^{b}$ Isolated yields. ${ }^{c} 80{ }^{\circ} \mathrm{C} .{ }^{d} 60{ }^{\circ} \mathrm{C}$.

product 3a in $69 \%$ yield (Table 1 , entry 8 ). Then, CuCl or DBU was used instead of $\mathrm{Cs}_{2} \mathrm{CO}_{3}$ but lower yields of $\mathbf{3 a}$ were isolated (Table 1, entries 9 and 10). The best results were observed when an additional additive such as $\mathrm{Cs}_{2} \mathrm{CO}, \mathrm{CuCl}_{2}$ or DBU was not added to reaction system, then 3 a was obtained in $84 \%$ yield (Table 1, entry 11). Thus, it was deduced that external base was not necessary and the starting material amine perhaps acted as an efficient enough base. This amination phosphinyl azide protocol was also dependent on the temperature; for example, when this reaction was performed at $80^{\circ} \mathrm{C}$, 3a was obtained only in $32 \%$ yield (Table 1 , entry 12 ) and at $60^{\circ} \mathrm{C} 3 \mathbf{a}$ was not obtained at all (Table 1, entry 13). So, the optimal reaction condition was at $120{ }^{\circ} \mathrm{C}$ for $12 \mathrm{~h}$ without any additive.

With the optimized reaction conditions in hand, we then evaluated the scope of amination using phosphoryl azides with various amines. As shown in Table 2 , substrates with a variety of primary amines and second amines afforded the products in good to excellent yields under the optimum reaction conditions. First, a range of primary amines, such as $n$-propylamine, $n$ butylamine, isobutylamine and isopropyl amine, were reacted with diphenyl phosphoryl azide to furnish 3a-3d in excellent yields under the optimized reaction condition. In contrast, tertbutylamine required a longer time of $24 \mathrm{~h}$ to afford only a 55\% isolated yield of 3e. The reason is that tert-butanol exhibits weak nucleophilicity. Primary amines containing electron-donating substituents, e.g., methoxy $\left(-\mathrm{OCH}_{3}\right)$ and electron-withdrawing $\left(-\mathrm{CF}_{3}\right)$, were tolerated and react with diphenyl phosphoryl azide to give good yields of phosphoramidates $3 \mathrm{f}-3 \mathrm{~g}$ in $85 \%$ and $52 \%$, respectively.

Table 2 Amination phosphoryl azides used for the synthesis of phosphoramidates $^{a}$

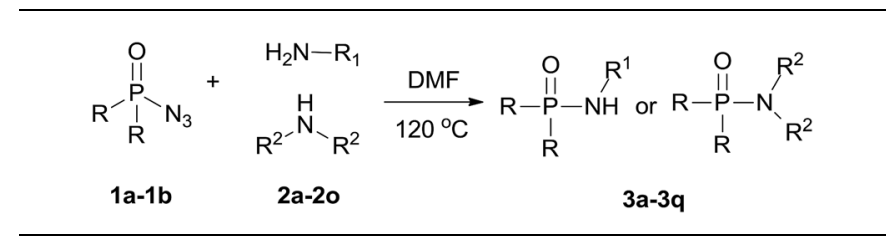

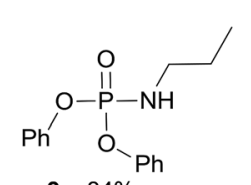

$3 a, 84 \%$<smiles>CC(C)NP(=O)(Oc1ccccc1)Oc1ccccc1</smiles>

$3 d, 81 \%$

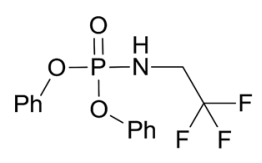

$3 g, 52 \%$

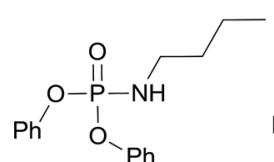

3b, $81 \%$<smiles>CC(C)CNP(=O)(Oc1ccccc1)Oc1ccccc1</smiles>

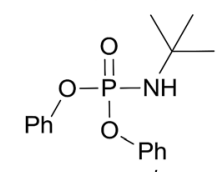

$3 e, 55 \%^{b}$

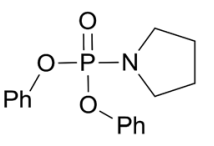

3h, $85 \%$

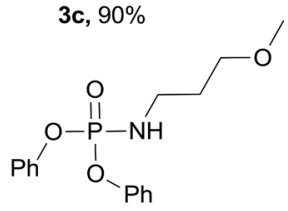

3f, $85 \%$<smiles>COc1ccc(CNP(=O)(Oc2ccccc2)Oc2ccccc2)cc1</smiles><smiles>CC(C)(C)[13CH2][13CH2]c1ccc(CNP(=O)(Oc2ccccc2)Oc2ccccc2)cc1</smiles>

$3 \mathrm{~m}, 85 \%$

3n, $81 \%$<smiles>O=P(Oc1ccccc1)(Oc1ccccc1)N1CCCCC1</smiles>

$3 \mathbf{i}, 78 \%$

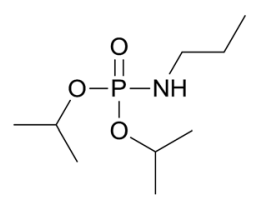

$3 p, 83 \%$

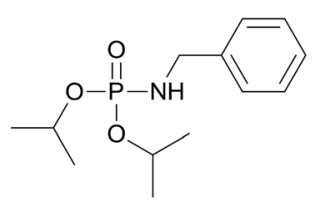

$3 q, 75 \%$
${ }^{a}$ Reaction conditions: diphenyl phosphoryl azide $\mathbf{1 a}(0.2 \mathrm{mmol})$, amine 2a-2o (0.4 mmol), DMF (2 mL), in a $25 \mathrm{~mL}$ Schlenk tube, $120{ }^{\circ} \mathrm{C}, 12 \mathrm{~h}$. b $24 \mathrm{~h}$.

When secondary cyclic amines such as tetrahydropyrrole, piperidine and morpholine were employed, the corresponding phosphoramidates yields turned out to be $85 \%, 78 \%$ and $90 \%$, respectively (3h-3j). A benzylamine bearing an electrondonating substituent $(\mathrm{Cl})$ or electron-withdrawing substituent $\left(\mathrm{OCH}_{3}\right)$ proceeded smoothly to afford the corresponding products in $92 \%$ and $85 \%$ isolated yields, respectively, and there was no sharp difference. 3-(Aminomethyl)pyridine and 2-thiophenemethylamine also served as good substrates to produce the corresponding phosphoramidates $\mathbf{3 n - 3 o}$ in excellent yields. 
Next, the reaction scope was extended to different phosphoryl azides; for example, diisopropyl phosphoryl azide also reacted with $n$-propylamine and benzylamine smoothly, affording the desired products $\mathbf{3 p}$ and $\mathbf{3 q}$ in $83 \%$ and $75 \%$ yields, respectively.

To get more information on the reaction mechanism, the next control experiment was performed with diphenyl phosphoryl azide 1a, diisopropyl hydrogen phosphate $\mathbf{1 b}$ and $n$ propylamine 2a subjected to the reaction under standard conditions. As shown below, 3a was obtained in 55\% yield, while 3p was not detected at all (eqn (2)), indicating that phosphoryl azide was not transformed to hydrogen phosphate and then attacked by amine to phosphoramidate, so hydrogen phosphate is not an intermediate. To investigate the sources of nitrogen-atoms and the alkyl group, diphenyl phosphoryl azide 1a, triethylamine $2 \mathbf{r}$ and $n$-propylamine $2 \mathbf{a}$ were reacted under the standard conditions. 3a was obtained in $71 \%$ yield, whereas 3r was not detected at all, showing that the reaction proceeds via a direct nucleophilic substitution at the $\mathrm{P}$ center, with the azide anion serving as the leaving group (eqn (3)).

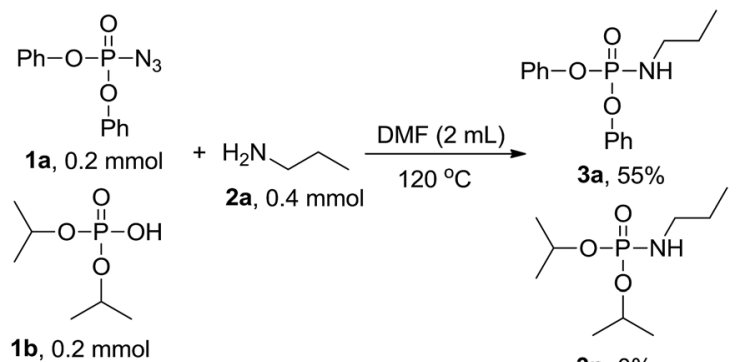

$3 p, 0 \%$

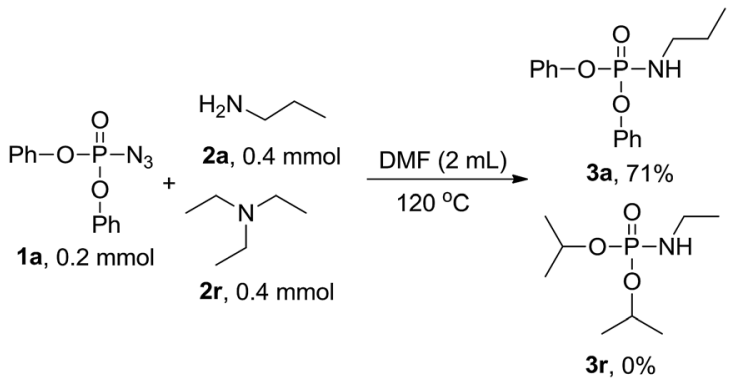

Based on the present results and the reported literature, ${ }^{17}$ a possible mechanism for the amination of phosphoryl azides in the synthesis of phosphoramidates is suggested in Scheme 1. First, phosphoryl azide $\mathbf{1}$ is attacked by amine $\mathbf{2}$ to form intermediate $\mathbf{m}$ via a nucleophilic addition, with the azide anion

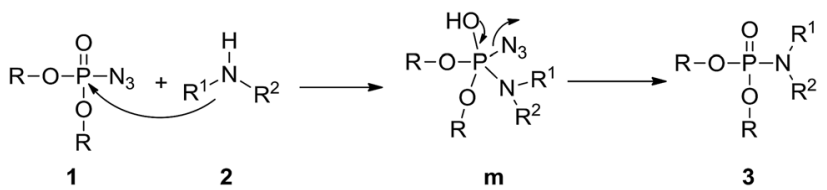

Scheme 1 Plausible reaction pathway for the synthesis of phosphoramidate 3 . serving as the leaving group by $\mathrm{P}-\mathrm{N}_{3}$ bond cleavage affording the desired phosphoramidate 3 .

\section{Conclusions}

In summary, we have developed a simple and highly efficient method for the synthesis of phosphoramidates via amination with phosphoryl azides under metal and base free conditions. The presented method exhibits a series of attractive features: good functional-group tolerance, metal and base free conditions and phosphoramidates synthesis via one reaction system. This is a straightforward, efficient and environmentally friendly alternative method for the preparation of industrially useful phosphoramidate derivatives.

\section{Conflicts of interest}

There are no conflicts to declare.

\section{Acknowledgements}

Financial support by National Natural Science Foundation of China (21603068), and research fund for the doctoral program of Hubei University of Science and Technology (2016-19XB011) are gratefully appreciated.

\section{Notes and references}

1 (a) J. W. Darrow and D. G. Drueckhammer, J. Org. Chem., 1994, 59, 2976; (b) W. Tang and X. Zhang, Chem. Rev., 2003, 103, 3029; (c) L. Bialy and H. Waldmann, Angew. Chem., Int. Ed., 2005, 44, 3814; (d) R. Zhuang, J. Xu, Z. Cai, G. Tang, M. Fang and Y. Zhao, Org. Lett., 2011, 13, 2110; (e) D. Zhao and R. Wang, Chem. Soc. Rev., 2012, 41, 2095.

2 (a) C. S. Demmer, N. Krogsgaard-Larsen and L. Bunch, Chem. Rev., 2011, 111, 7981; (b) T. Olszewski, Synthesis, 2014, 46, 403; (c) S. Demkowicz, J. Rachon, M. Dasko and W. Kozak, RSC Adv., 2016, 6, 7101; (d) M. Serpi, R. Bibbo, S. Rat, H. Roberts, C. Hughes, B. Caterson, M. J. Alcaraz, A. T. Gibert, C. R. A. Verson and C. McGuigan, J. Med. Chem., 2012, 55, 4629.

3 (a) X. Gao, Z. Tang, M. Lu, H. Liu, Y. Jiang, Y. Zhaoc and Z. Cai, Chem. Commun., 2012, 48, 10198; (b) B. Li, R. D. Simard and A. M. Beauchemin, Chem. Commun., 2017, 53, 8667; (c) M. Neisius, S. Liang, H. Mispreuve and S. Gaan, Ind. Eng. Chem. Res., 2013, 52, 9752.

4 (a) J. I. Guijarro, J. E. González-Pastor, F. Baleux, J. L. S. Millán, M. A. Castilla, M. Rico, F. Moreno and M. Delepierre, J. Biol. Chem., 1995, 270, 23520; (b) C. Grison and T. K. Olszewski, Heteroat. Chem., 2008, 19, 461; (c) T. K. Olszewski, C. Bomont, P. Coutrot and C. Grison, J. Organomet. Chem., 2010, 695, 2354; (d) T. K. Olszewski and C. Grison, Heteroat. Chem., 2010, 21, 139. 5 (a) R. A. Dwek, Chem. Rev., 1996, 96, 683; (b) T. M. Nguyen, S. Chang, B. Condon, R. Slopek, E. Graves and M. Yoshioka-Tarver, Ind. Eng. Chem. Res., 2013, 52, 4715. 
6 (a) M. J. Berridge and R. F. Irvine, Nature, 1989, 341, 197; (b) P. Garcia, Y. Y. Lau, M. R. Perry and L. L. Schafer, Angew. Chem., Int. Ed., 2013, 52, 9144.

7 (a) K. Wittine, K. Benci, Z. Rajić, B. Zorc, M. Kralj, M. Marjanović, K. Pavelić, E. De Clercq, G. Andrei, R. Snoeck, J. Balzarini and M. Mintas, Eur. J. Med. Chem., 2009, 44, 143; (b) R. F. Roush, E. M. Nolan, F. Löhr and C. T. Walsh, J. Am. Chem. Soc., 2008, 130, 3603; (c) W. P. Roberts, M. E. Tate and A. Kerr, Nature, 1977, 265, 379.

8 (a) C. Nguyen and A. Kim, Macromol. Res., 2008, 16, 620; (b) K. Faghihi, M. Hajibeygi and M. Shabanian, Macromol. Res., 2009, 17, 739; (c) X. Zhao, H. V. Babu, J. Llorca and D. Y. Wang, RSC Adv., 2016, 6, 59226.

9 (a) S. E. Denmark and G. L. Beutner, Angew. Chem., Int. Ed., 2008, 47, 1560; (b) O. Molt and T. Schrader, Synthesis, 2002, 2633; (c) P. Garcia, Y. Y. Lau, M. R. Perry and L. L. Schafer, Angew. Chem., Int. Ed., 2013, 52, 9144; (d) W. Liu, C. Zheng, C. Zhuo, L. Dai and S. You, J. Am. Chem. Soc., 2012, 134, 4812.

10 (a) L. D. Quin, A Guide to Organophosphorus Chemistry, Wiley, New York, 2000; (b) N. Z. Kiss and G. Keglevich, Curr. Org. Chem., 2014, 18, 2673; (c) P. Wyatt, H. Eley, J. Charmant, B. J. Daniel and A. Kantacha, Eur. J. Org. Chem., 2003, 4216.

11 (a) F. R. Atherton, H. T. Openshaw and A. R. J. Todd, J. Chem. Soc., 1945, 660; (b) F. R. Atherton and A. R. J. Todd, J. Chem. Soc., 1947, 674; (c) G. Mielniczak and A. Bopusiński, Synth. Commun., 2003, 33, 3851.
12 (a) X. Jin, K. Yamaguchi and N. Mizuno, Org. Lett., 2013, 15, 418; (b) J. Dhineshkumar and K. R. Prabhu, Org. Lett., 2013, 15, 6062; (c) Y. Zhou, J. Yang, T. Chen, S. Yin, D. Han and L. Han, Bull. Chem. Soc. Jpn., 2014, 87, 400; (d) J. Fraser, L. J. Wilson, R. K. Blundell and C. J. Hayes, Chem. Commun., 2013, 49, 8919; (e) B. Ahmad Dar, N. A. Dangroo, A. Gupta, A. Wali, M. A. Khuroo, R. A. Vishwakarma and B. Singh, Tetrahedron Lett., 2014, 55, 1544; $(f)$ R. Zhu, C. Pan and Z. Gu, Org. Lett., 2015, 17, 5862; (g) M. Meazza, A. Kowalczuk, L. Shirley, J. W. Yang, H. Guo and R. Rios, Adv. Synth. Catal., 2016, 358, 719.

13 (a) I. Wilkening, G. del Signore and C. P. R. Hackenberger, Chem. Commun., 2008, 2932; (b) B. Wahl, A. Cabre, S. Woodward and W. Lewis, Tetrahedron Lett., 2014, 55, 5829.

14 G. Hong, X. Zhu, C. Hu, A. N. Aruma, S. Wu and L. Wang, J. Org. Chem., 2016, 81, 6867.

15 M. M. I. Basiouny and J. A. R. Schmidt, Organometallics, 2017, 36, 721.

16 (a) H. Lu, J. Tao, J. E. Jones, L. Wojtas and X. P. Zhang, Org. Lett., 2010, 12, 1248; (b) W. Xiao, C. Zhou and C. Che, Chem. Commun., 2012, 48, 5871; (c) H. Kim, J. Park, J. G. Kim and S. Chang, Org. Lett., 2014, 16, 5466; (d) C. Pan, Y. Wang, C. $\mathrm{Wu}$ and J. Yu, Org. Biomol. Chem., 2018, 16, 3711; (e) C. Pan, N. Jin, H. Zhang, J. Han and C. Zhu, J. Org. Chem., 2014, 79, 9427.

17 S. Y. Chow, M. Y. Stevens and L. R. Odell, J. Org. Chem., 2016, 81, 2681. 